\title{
Histiocytic lymphadenopathy secondary to metallosis following endoprosthetic replacement in osteosarcoma patient - a potential diagnostic pitfall
}

\author{
Kamil Sokół1,2, Bartłomiej Szostakowski³ , Maria Chraszczewska1,2, Tomasz Goryń3, \\ Michał Wągrodzki ${ }^{1}$, Monika Prochorec-Sobieszek1,2, Anna Szumera-Ciećkiewicz ${ }^{1,2}$
}

'Department of Pathology and Laboratory Diagnostics, Maria Sklodowska-Curie National Research Institute of Oncology, Warsaw, Poland
2Department of Diagnostic Hematology, Institute of Hematology and Transfusion Medicine, Warsaw, Poland
${ }^{3}$ Department of Soft Tissue/Bone Sarcoma and Melanoma, Maria Sklodowska-Curie National Research Institute of Oncology, Warsaw, Poland

We present the case of a 43-year old patient with inguinal lymphadenopathy 22 years after distal femoral resection for osteosarcoma with cemented distal femoral replacement reconstruction. Seven years after initial distal femoral resection patient underwent metal on metal hip resurfacing arthroplasty on the affected side. Twenty years after distal femoral replacement and 13 years after metal on metal hip resurfacing procedure, the patient underwent left inguinal lymphadenectomy for an enlarged mass of inguinal lymph nodes on suspicion for a sarcoma recurrence. On microscopic examination, excised lymph nodes were massively infiltrated with macrophages and multinucleated giant cells with focal asteroid bodies. An examination in polarized light revealed numerous metal particles; immunohistochemical stainings confirmed reactive character of changes, and florid metal-related sinus histiocytosis was finally diagnosed. Microscopic assessment of lymph nodes in the course of malignancy is a standard procedure; we present a rare case of non-neoplastic lymph node enlargement due to the late onset of metallosis, which might be a diagnostic challenge.

Key words: metallosis, osteosarcoma, lymphadenopathy, endoprosthesis, metal on metal

\section{Introduction}

Lymphadenopathy in patients who underwent osteosarcoma treatment firstly suggests metastatic spread, however other potential causes must also be considered as lymph nodes are parts of an immune system which functions include filtration of various antigens from the extracellular fluid. Lymph nodes consist of macrophages, lymphocytes, and antigen-presenting cells, depending on the immunological status, age, and localization [1]. Essential differential diagnosis of enlarged lymph nodes leads to classification into one of a category: infectious (fungal, viral, protozoal, bacterial), inflammatory (drug, foreign body), neoplastic (primary neoplasm, metas- tasis), trauma, autoimmune, idiopathic (e.g., sarcoidosis). Often hematoxylin and eosin staining can target differential diagnostics; usually, additional immunohistochemical and/ or histochemical evaluation is necessary. The critical point to the exclusion of sarcoma metastasis or primary lymph node malignancy (lymphoma) is morphology. In the histopathological assessment of osteosarcoma, no specific antibodies are routinely used, and in the absence of data from the medical history or a non-specific microscopic appearance, a broad immunohistochemical panel is used to narrow down the diagnosis. In the presence of foreign particles, it is suggested to perform the microscopic evaluation in polarized

\section{How to cite:}

Sokół K, Szostakowski B, Chraszczewska M, Goryń T, Wągrodzki M, Prochorec-Sobieszek M, Szumera-Ciećkiewicz A. Histiocytic lymphadenopathy secondary to metallosis following endoprosthetic replacement in osteosarcoma patient-a potential diagnostic pitfall. NOWOTWORY J Oncol 2020; 70: 272-275. 
light; some metal particles, including steel alloys, may exhibit birefringence with pale green luminescence $[2,3]$.

In our paper, we present a case of histiocytic lymphadenopathy secondary to metallosis following limb-sparing surgery for osteosarcoma and metal on metal hip resurfacing on the affected size. The differential diagnosis with a discussion of overlapping morphological images are revised.

\section{Material and methods}

\section{Clinical history}

A 43-year-old Caucasian male was admitted to the hospital due to enlarging left inguinal mass. In 1998 patient underwent limb-sparing resection and reconstruction of the distal femur for a classical high-grade osteosarcoma (fig. 1: A, B). The patient was initially fitted with a cemented distal femoral replacement in 1998, followed by metal on metal hip resurfacing in 2005 for hip arthritis (fig.1: C, D). The patient had a soft tissue relapse of osteosarcoma in 2002 that was treated with a second-line chemotherapy and radical excision. Due to previous oncological history, the enlarged inguinal mass was suspected to be a metastatic relapse of osteosarcoma. Ultrasound examination showed enlarged lymph nodes - the largest measuring $28 \mathrm{~mm}$ in diameter. Radiologist described lymph nodes as suspicious for a neoplastic process. Fine needle biopsy of the lymph node showed only elements of a peripheral blood smear. There were no significant changes in laboratory tests. Lymph nodes were surgically removed and examined histopathologically.

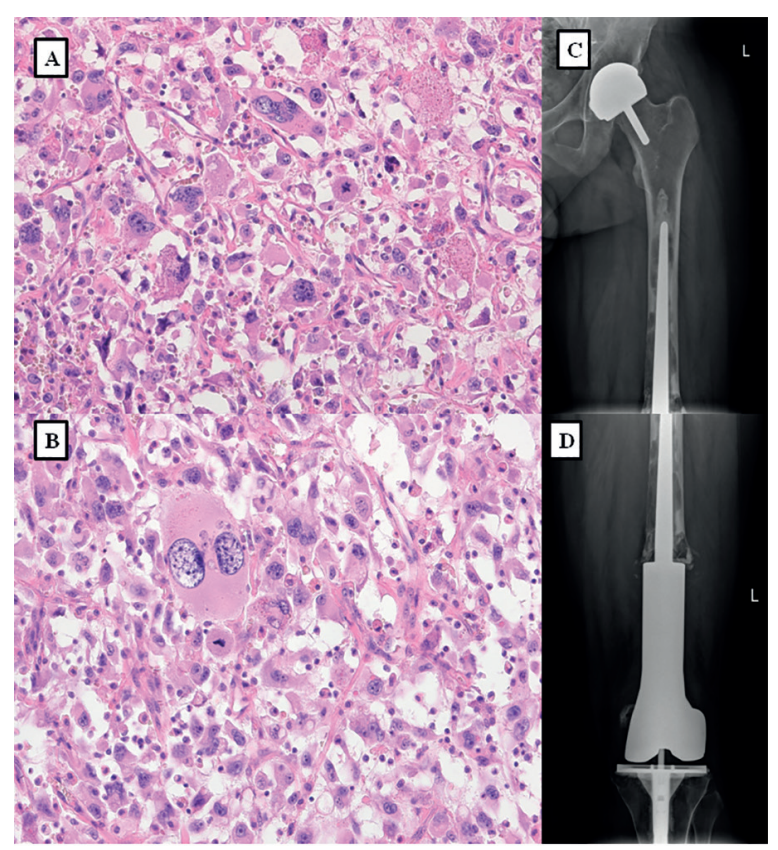

Figure 1. A, B - microscopic presentation of primary bone osteosarcoma, highly apoptotic with scattered "giant" neoplastic cells (A - HE, 200x; B - HE, 400x); C, D - X-ray showing cemented distal femoral replacement and metal on metal hip resurfacing in 2013 and in 2018 when the progression of a stem loosening and cortical thinning is clearly visible

\section{Histopathology}

The resected lymph nodes were fixated with $4 \%$ formalin and paraffin-embedded; the five $\mu$ m-thick sections were made for hematoxylin and eosin staining (HE), Grocott-Gomori's methenamine silver (GMS), Periodic acid-Schiff (PAS), acid-fast stain (AFB), and immunostained with S100 (RTU, DAKO-Agilent, CD23 (RTU, DAK-23, DAKO-Agilent), CD20 (RTU, L26, DAKO-Agilent), Ki-67 (RTU, MIB-1, DAKO-Agilent), CD68 (RTU, KP1, DAKO-Agilent), CD163 (RTU, MRQ-26, Cell Marque), CD1a (RTU, 010, DAKO-Agilent), CD3 (1:50, F7.2.38, DAKO-Agilent).

\section{Results}

\section{Histopathological and immunohistochemical findings and visualization in polarized light}

Microscopically, a reactive lymph node with massive histiocytic and macrophage infiltration. There were many giant multinucleated cells, some with asteroid bodies. Macrophages showed a lot of "dust" particles that were bright green in the polarized light. The histochemical stains (PAS, GMS, AFB) did not indicate any microorganisms; $C D 3$ showed normal mantle distribution of small T-cells, CD20 pointed germinal center B-cells, CD23 revealed a typical structure of dendritic cells in the germinal center, there were few Langerhans cells CD1a-positive. Macrophage infiltration was CD68KP1 and CD163-positive. Ki-67 was high in germinal centers; it was low, below $5 \%$ elsewhere. Finally, the diagnosis of florid metal-related sinus histiocytosis was made. The histopathological, immunohistochemical, and polarized light images are presented in figure 2 .

\section{Discussion}

Bone malignant neoplasms are relatively rare and consist of only $0.2 \%$ of incidents of malignancies in Poland [4]. There are twice as frequent in men as in women. The most common bone sarcoma is osteosarcoma, with 60-100 new incidents per year. Osteosarcoma has a bimodal age distribution, having the first peak during adolescence and the second peak in older adulthood [5]. Osteosarcoma develops most often at the metaphysis of lower extremity long bones ( $75 \%$ of cases). Histologically osteosarcoma demonstrates malignant spindle cells with pleomorphic nuclei, scattered mitotic figures, and varying levels of anaplasia. Conventional osteosarcomas are classified into osteoblastic, chondroblastic, or fibroblastic types, depending on which matrix-producing cells dominate [6-8].

Before the development of chemotherapy, osteosarcoma was a fatal disease with severe outcomes. Patients with locally advanced tumors used to develop metastases in the lungs and bone marrow quickly and died a few months after [9]. Less common histological subtypes like osteoblastoma-like and chondroblastoma-like osteosarcoma more common metastasize than its' conventional counterparts [10]. Metastases of osteosarcoma in lymph nodes are rare entities; most reports estimate that it occurs in about $1-4 \%$ of patients with 


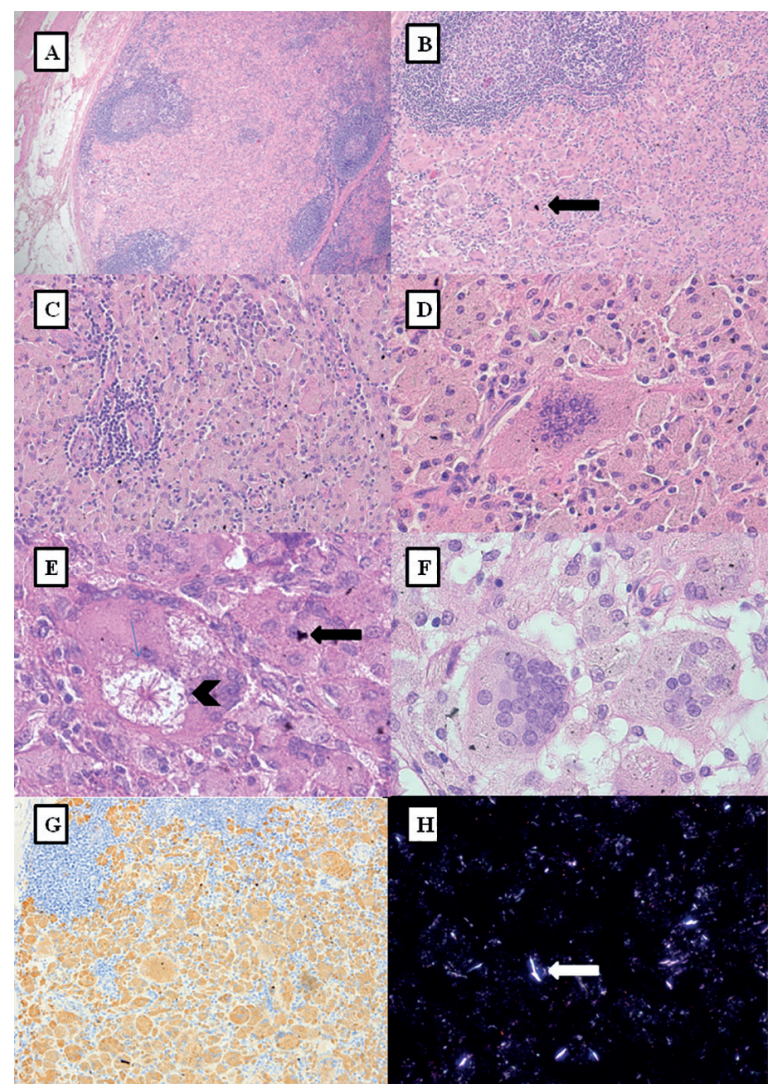

Figure 2. Metal-related sinus histiocytosis. A, B, C - lymph node with massive histiocytic and macrophage infiltration, with sparse typical germinal centers preserved (A - HE, 20x, B - 100x, C- 200x); D, E, $\mathbf{F}$ - giant multinucleated Langhans cells, some with asteroid bodies (arrowhead) and macrophages with black metal "dust" (arrow) which were released from endoprosthesis ( $D-H E, 400 x, E-H E$, 1000x, F - HE, 600x); G - CD63 diffuse positive reaction among macrophages (CD163, 200x); $\mathbf{H}$ - macrophages are presenting with the "dust" bright particles in the polarized light (HE, polarized light, 400x)

osteosarcoma [11, 12]. We found no literature describing any connection between the histological type of osteosarcoma and lymph node metastases rate. Adjuvant chemotherapy and surgery procedures highly improve outcomes [10, 13]. Development of modern endoprosthetic reconstruction techniques and the introduction of modular tumor endoprostheses heavily reduced the number of amputations in osteosarcoma patients $[9,14,15]$.

Endoprostheses of joints can wear in time, producing debris particles in surrounding tissues [16-18]. The generation of wear debris from any part of the prosthesis is unavoidable. Implant loosening secondary to osteolysis is the most common mode of failure of arthroplasty [19]. Local and regional lymphadenopathy that is caused by wear particles released from a joint-replacement prosthesis is increasingly becoming recognized as a possible complication of arthroplasty [20]. Accumulation of such particles causes an inflammatory response, including macrophagic activation with the formation of giant cells and fibrosis. Soft tissue infiltration by metal debris shed by the prosthesis or lymphatic uptake of metal debris following its wear is called metallosis [17, 21].
Local lymphadenopathy in patients with endoprosthetic reconstruction needs differential diagnosis of join infection, implant-associated allergic reaction, or hypersensitivity related to implant itself. In some cases, those particles from prosthesis are drained through lymph vessels to regional lymph nodes $[3,22]$. Accumulation of histiocytes with the debris is responsible for the enlarging of lymph nodes - some histocytes fuse in multinucleated giant cells [20]. Metallic particles are usually seen as very small $(0,5-5 \mu \mathrm{m})$ dark brown or black bodies. Other components of a prosthesis (usually polyethylene, polymethylmethacrylate) are bright and not seen in HE staining in a light microscope, but are bright in polarized light [23].

It has to be emphasized that only some of the patients after joint replacement surgery develop lymphadenopathy [3]. Different studies describe that the metallosis rate depends on materials and operated joint and happened in about 5-23\% of patients $[17,21]$. It seems that there is no explanation for this phenomenon. In animal models, $1 \%$ of radioactive label particles injected intra-articular sites migrated to regional lymph nodes after 24. In a similar experiment, radioactive label particles were injected into femur bone marrow. In that case, particles moved to the lung via the blood vessels within $15 \mathrm{sec}$ onds, and no migration to the lymph node was detected [20].

Histologically, asteroid body is characteristic but not specific microscopical finding. Although it is commonly associating with sarcoidosis [24] and may occur in different pathological diagnoses. e.g. foreign body reaction in silicon transplant leaking $[25,26]$, other foreign body reaction [27], fungal infection [28], rarely in some neoplasm [29]. As in our case, palpably asteroid body mechanism of creation is similar for that in foreign body reactions $[30,31]$.

Besides local symptoms, the presence of metal and ethylene particles in a human body may also cause generalizes symptoms like cardiomyopathy, neuropathy, psychological status changes, skin rash, visual impairment [17]. It is essential to recognize this state and introduce treatment before generalized symptoms occurred. Treatment includes surgical revision of prosthesis, removal of damaged parts, and changed tissues and bone grafting $[17,21]$.

\section{Conclusion}

Enlarged lymph nodes in tumor surgery patients may be suggestive of a recurrence of the malignancy; however, both neoplastic and non-neoplastic conditions must also be considered. We presented a case of a lymph node foreign body reaction in the form of florid histiocytosis in osteosarcoma patient after long-term follow up of both limb-sparing surgery with massive endoprosthetic reconstruction and metal on metal hip resurfacing. It is important to know that both implants are prone to massive wear debris, especially after long term follow up, resulting in catastrophic failures [32, 33]. Histiocytic lymphadenopathy secondary to metallosis in patients who underwent joint replacement surgery is usually indicative 
of increased endoprosthetic wear that requires immediate attention, usually followed by revision surgery. It is paramount to compare both clinical and radiological presentation for a complete image.

\section{Acknowledgments}

This work has been supported by the Project infrastructure POIG.02.03.00-14-111/13 funded by Operational Programme Innovative Economy 2007-2013, Priority II. R\&D Infrastructure, Measure 2.3. Investments connected with the development of the IT infrastructure of Science.

\section{Conflict of interest: none declared}

\section{Anna Szumera-Ciećkiewicz}

Maria Sklodowska-Curie National Research Institute of Oncology Department of Pathology and Laboratory Diagnostics

ul. Roentgena 5

02-781 Warszawa, Poland

e-mail: szumann@gmail.com

Received: 1 Jun 2020

Accepted: $5 \mathrm{Jul} 2020$

\section{References}

1. Willard-Mack CL. Normal structure, function, and histology of lymph nodes. Toxicol Pathol. 2006; 34(5): 409-424, doi: 10.1080/01926230600867727, indexed in Pubmed: 17067937.

2. Stewart AJ, Southcott BM, Raweily E. Lymphadenopathy after joint replacement for osteoclastoma. J R Soc Med. 2003; 96(8): 404-406, doi: 10.1258/jrsm.96.8.404, indexed in Pubmed: 12893861.

3. Calo C, Preston H, Clements A. Retroperitoneal lymphadenopathy secondary to joint replacement wear and debris, a case report. Gynecol Oncol Rep. 2018; 23: 10-12, doi: 10.1016/j.gore.2017.12.003, indexed in Pubmed: 29892683.

4. Wojciechowska U, Didkowska J, Olasek P. Nowotwory złośliwe w Polsce w 2015 roku - Cancer in Poland in 2015. Krajowy Rejestr NowotworówZakład Epidemiologii i Prewencji Nowotworów, Warszawa 2017.

5. Ottaviani G, Jaffe N. The epidemiology of osteosarcoma. Cancer Treat Res. 2009; 152: 3-13, doi: 10.1007/978-1-4419-0284-9_1, indexed in Pubmed: 20213383.

6. Czerniak B. Dorfman and Czerniak's Bone Tumors, 2nd ed. Elsevier 2015.

7. Dorfman HD, Czerniak B. Bone cancers. Cancer. 1995; 75(1 Suppl): 203-210, doi: 10.1002/1097-0142(19950101)75:1+<203::aid-cncr2820751308>3.0.co;2-v, indexed in Pubmed: 8000997.

8. Fletcher C, Bridge J, Hogendoorn P, Mertens F. WHO Classification of Tumours of Soft Tissue and Bone, 4th ed. IARC, Lyon 2013.

9. Durfee RA, Mohammed M, Luu HH. Review of Osteosarcoma and Current Management. Rheumatol Ther. 2016; 3(2): 221-243, doi: 10.1007/ s40744-016-0046-y, indexed in Pubmed: 27761754.

10. Klein MJ, Siegal GP. Osteosarcoma: anatomic and histologic variants. Am J Clin Pathol. 2006; 125(4): 555-581, doi: 10.1309/UC6K-QHLD-9LV2-KENN, indexed in Pubmed: 16627266.

11. Dirik Y, Çınar A, Yumrukçal F, et al. Popliteal lymph node metastasis of tibial osteoblastic osteosarcoma. Int J Surg Case Rep. 2014; 5(11): 840 844, doi: 10.1016/j.jijscr.2014.09.029, indexed in Pubmed: 25462047.

12. Thampi S, Matthay KK, Goldsby R, et al. Adverse impact of regional lymph node involvement in osteosarcoma. Eur J Cancer. 2013; 49(16): 3471-3476, doi: 10.1016/j.ejca.2013.06.023, indexed in Pubmed: 23867123.

13. Whelan JS, Bielack SS, Marina N, et al. EURAMOS collaborators. EURAMOS-1, an international randomised study for osteosarcoma: results from pre-randomisation treatment. Ann Oncol. 2015; 26(2): 407-414, doi: 10.1093/annonc/mdu526, indexed in Pubmed: 25421877.

14. Hwang JS, Mehta AD, Yoon RS, et al. From amputation to limb salvage reconstruction: evolution and role of the endoprosthesis in musculo- skeletal oncology. J Orthop Traumatol. 2014; 15(2):81-86, doi: 10.1007/ s10195-013-0265-8, indexed in Pubmed: 24057576.

15. Isakoff MS, Bielack SS, Meltzer P, et al. Osteosarcoma: Current Treatment and a Collaborative Pathway to Success. J Clin Oncol. 2015; 33(27): 3029-3035, doi: 10.1200/JCO.2014.59.4895, indexed in Pubmed: 26304877.

16. Rakow A, Schoon J, Dienelt A, et al. Influence of particulate and dissociated metal-on-metal hip endoprosthesis wear on mesenchymal stromal cells in vivo and in vitro. Biomaterials. 2016; 98: 31-40, doi: 10.1016/j.biomaterials.2016.04.023, indexed in Pubmed: 27179133.

17. Oliveira CA, Candelária IS, Oliveira PB, et al. Metallosis: A diagnosis not only in patients with metal-on-metal prostheses. Eur J Radiol Open. 2015; 2: 3-6, doi: 10.1016/j.ejro.2014.11.001, indexed in Pubmed: 26937430.

18. Natu S, Sidaginamale RP, Gandhi J, et al. Adverse reactions to metal debris: histopathological features of periprosthetic soft tissue reactions seen in association with failed metal on metal hip arthroplasties. J Clin Pathol. 2012; 65(5): 409-418, doi: 10.1136/jclinpath-2011-200398, indexed in Pubmed: 22422805.

19. Bitar D, Parvizi J. Biological response to prosthetic debris. World J Orthop. 2015; 6(2): 172-189, doi: 10.5312/wjo.v6.i2.172, indexed in Pubmed: 25793158.

20. Benz EB, Sherburne B, Hayek JE, et al. Lymphadenopathy associated with total joint prostheses. A report of two cases and a review of the literature. J Bone Joint Surg Am. 1996; 78(4): 588-593, doi: 10.2106/00004623-199604000-00014, indexed in Pubmed: 8609139.

21. Khan WS, Agarwal M, Malik AA, et al. Chromium, cobalt and titanium metallosis involving a Nottingham shoulder replacement. J Bone Joint Surg Br. 2008; 90(4): 502-505, doi: 10.1302/0301-620X.90B4.20302, indexed in Pubmed: 18378928.

22. Davies AM, Cooper SA, Mangham DC, et al. Metal-containing lymph nodes following prosthetic replacement of osseous malignancy: potential role of MR imaging in characterisation. Eur Radiol. 2001; 11(5): 841-844, doi: 10.1007/s003300000666, indexed in Pubmed: 11372619.

23. Baslé MF, Bertrand G, Guyetant $\mathrm{S}$, et al. Migration of metal and polyethylene particles from articular prostheses may generate lymphadenopathy with histiocytosis. J Biomed Mater Res. 1996; 30(2): 157-163, doi: 10.1002/(SICI)1097-4636(199602)30:2<157::AID-JBM4>3.0.CO;2-Q, indexed in Pubmed: 9019479

24. Ma Y, Gal A, Koss M, et al. The pathology of pulmonary sarcoidosis: update. Semin Diagn Pathol. 2007; 24(3): 150-161, doi: 10.1053/j. semdp.2007.06.002, indexed in Pubmed: 17882899.

25. Malzone MG, Campanile AC, Gioioso A, et al. Silicone lymphadenopathy: presentation of a further case containing asteroid bodies on fine-needle cytology sample. Diagn Cytopathol. 2015; 43(1): 57-59, doi: 10.1002/ dc.23123, indexed in Pubmed: 24995825.

26. van Diest PJ, Beekman WH, Hage JJ. Pathology of silicone leakage from breast implants. J Clin Pathol. 1998; 51(7): 493-497, doi: 10.1136/ jcp.51.7.493, indexed in Pubmed: 9797723.

27. Gouvêa AF, Hanemann JA, Pereira AA, et al. Uncommon foreign body reactions occurring in the lip: clinical misdiagnosis and the use of special techniques of analysis. Head Neck Pathol. 2011; 5(1): 86-91, doi: 10.1007/s12105-010-0217-z, indexed in Pubmed: 21046297.

28. Guarner J, Brandt ME. Histopathologic diagnosis of fungal infections in the 21st century. Clin Microbiol Rev. 2011; 24(2): 247-280, doi: 10.1128/ CMR.00053-10, indexed in Pubmed: 21482725.

29. Patil S, Rao RS, Amrutha N. A Spider like body in Keratocystic Odontogenic Tumor - A Paradoxical find. J Int Oral Health. 2013; 5(6): 131-133, indexed in Pubmed: 24453458.

30. Anderson JM, Rodriguez A, Chang DT. Foreign body reaction to biomaterials. Semin Immunol. 2008; 20(2): 86-100, doi: 10.1016/j. smim.2007.11.004, indexed in Pubmed: 18162407.

31. Rodríguez G, Sarmiento $L$. The asteroid bodies of sporotrichosis. Am J Dermatopathol. 1998; 20(3): 246-249, doi: 10.1097/00000372199806000-00004, indexed in Pubmed: 9650696.

32. Ollivere B, Darrah C, Barker T, et al. Early clinical failure of the Birmingham metal-on-metal hip resurfacing is associated with metallosis and soft-tissue necrosis. J Bone Joint Surg Br. 2009; 91(8): 1025-1030, doi: 10.1302/0301-620X.91B8.21701, indexed in Pubmed: 19651828.

33. Shinto $Y, U$ chida $A$, Yoshikawa $\mathrm{H}$, et al. Inguinal lymphadenopathy due to metal release from a prosthesis. A case report. J Bone Joint Surg Br. 1993; 75(2): 266-269, doi: 10.1302/0301-620X.75B2.8444948, indexed in Pubmed: 8444948 